\title{
Using a virtual power plant to optimize the functionality of the resources distribution in the power system
}

\author{
Mostafa ESKANDARI ${ }^{1, *}$, Jafar Trfy FRD ${ }^{2}$, Jamal Gholami AHANGARAN ${ }^{3}$ \\ *Islamic Azad University graduate student Nain \\ Mostafa_eskandari68@yahoo.com
}

\begin{abstract}
Wind and solar power plants, are incurred almost zero marginal cost during the operation. However, the variable nature of these resources creates problems while requiring the power supply. Thus, non-distributable load power sources combine with productive resources that can distribute load, in the form of a virtual power plant. This study examines a self-organized virtual power plant using renewable energy resources, storage system and a traditional power plant. The problem of optimal power flow with linear programming model will be carried out in a week to maximize virtual power plant profits. Uncertainty due to the nature of solar and wind power with pumped storage power plant to take advantage of a more flexible generation process as well as a traditional power plant as a backup, will be eliminated. Efficiency of model is analyzed and presented, using a real sample. In addition, the effect of applying different capacity turbine pump and pumped storage power plant is analyzed. In order to optimize and maximize profits, genetic algorithm is employed.
\end{abstract}

Keywords: increased efficiency, virtual power plant, power supply, optimization, group control and condensing.

\section{INTRODUCTION}

Today's world need to electrical energy will not ever end. Because electrical energy forms the bulk of energy demand and the global demand for energy is increasing every day. Review of global energy demand was a project that took shape between 1990 and 2010 and it was investigated electrical energy demand in developing countries based on their population and economic growth. Maintenance and supply of electricity could not progress in accordance with demand growth and it was not enough for global demand. So, there was more willing to use fossil fuels, which were the main source of $\mathrm{CO} 2$ on Earth, to supply electrical loads. $90 \%$ of currently used fuels are made of carbon that their use results to $\mathrm{CO} 2$ generation.

Small power generation systems such as: micro hydro, photovoltaic, wind turbines and microturbines are widely being replaced with traditional power systems and are used for various applications. This generation systems are known as Distributed Generation DG. DG technology consists of small generation systems and power resources, and this collection is known as sources of energy distribution. Scattered distribution allows lowering construction costs related to the distribution substation, so that these resources can place next to loads which feed them. Creating economical and technical base to contribute these generation systems in electricity market, their competitiveness and consequently improving power supply are provided.

\footnotetext{
${ }^{1}$ Islamic Azad University graduate student Nain

${ }^{2}$ Islamic Azad University faculty member Ize

${ }^{3}$ Islamic Azad University faculty member Nain
} 
In traditional generation systems energy generation process has 4-step, including: generation, transmission, distribution and power consumption. On the other hand, there are modern generation system which unlike old systems generation is not operated only in first step and thus electric transition to customers is indirect. In recent years, regarding to diversity in loads and domination of large, centralized sources of power grid, system losses are increased and reliability is greatly reduced. DG sources have many positive features including high efficiency, low construction time, simple setup and little problems of this system that all these features helps these systems to be prevalent in power network. DG allows us to do necessary optimization between cost and reliability of our system and this means DGs can play a significant role in the electricity market.

These DGs are controlled freely and based on load condition that they feed. In addition, the lack of supply load in each of these resources is shared with other components through communication tool and this lack can be compensated by other sources. These conditions directly affects role of traditional generation sources as main network feeders, which causes rapid formation of network modern structures in supplying consumer demand. For example, restrictions on the generation and transfer to remote areas will be eliminated.

Exploiting modern energy distribution resources in power networks leads to develop new ideas, like micro-networks and virtual power plant. These new designs have different engineering theme rather than traditional system in their designing, and ability to increase efficiency, reliability, quality and security of electrification systems. Fortunately, in the near future, distributed generation resources control can create a powerful distribution system, independent of power network, other DGs, and other distributed control centers. These imply virtual power plant idea.

\section{Previous works}

Among existed technologies in electricity industry to control energy distribution resources, virtual power plant is one of the most modern and most efficient ones. Estiavan, 2007, presented a complete definition of virtual power plant and did definition and determination of different parts of virtual power plant and control systems. One of the other important concepts in exploitation of a virtual power plant that draw so much attention to it, corporation of virtual power plant in power market and economic optimization in the way incorporated resource produce in virtual power plant. Shee yoo, 2010, describes electricity market based on virtual power plant and how to exploit it practically by examining electricity market in northern Europe.

(H. E. khan and Herbert, 2011) are examined in their article how to control power transmission by virtual power plants which a method for controlling the flow of active and reactive power which will be transferred from the DG to consumers.

(Roge panzik, 2013) is addressed how to participate different generation resources into virtual power plants. He evaluates its performance by putting wind, solar, pumped storage and traditional power plants in the form of virtual power plants and incorporating this power plant to the power grid.

\section{Proposed method}

The basic idea in selection methods is that better people are preferred to the worse, the better and the worse are defined by the fitness function F. Several selection methods have been proposed to use in genetic algorithm. One of good feature for selection methods is that these methods are independent from population people Show, and only people fitness values are considered. Since there are several methods for selection operation in genetic algorithm and there is no space to explain all of these methods, this section only introduces the method (roulette wheel) we used in this simulation. Roulette wheel selection, first was suggested by "Holland", is one of the best random choices which its idea is probability of selection. Probability of selecting corresponding to 
each chromosome, is calculated based on its fitness that if it is $\mathrm{k}$-th chromosome fitness value, the probability of survival corresponding chromosomes will be:

$$
\mathrm{Pk}=\mathrm{fk} /\left(\sum \mathrm{ni}=1^{*} \text { fi }\right)
$$

Now, we sort chromosomes based on $\mathrm{pk}$ and $\mathrm{qk}$ which is cumulative values of $\mathrm{pk}$, is calculated as follows:

$$
\text { pi q } \mathrm{k}=\sum \mathrm{ki}
$$

Roulette wheel is operating so that, in order to select every chromosome, it generates a random number between 0 and 1 , and when mentioned number places in each interval corresponding chromosome is selected.

\subsection{Optimization using GA}

Before a genetic algorithm could have been performed, an appropriate encoding (representation) must be found for the problem. Also a fit function should create to correspond a value to any encoded solution. In this thesis, the objective function is calculated in equation (3). In order to maximize profits derived from the virtual power plant, costs of performance and profits should optimize through bilateral contracts. This process is repeated several times to produce the next generation population. Then the population will be examine and if the convergence criteria $i$ are met, this process is terminated.

$$
\begin{aligned}
& \operatorname{maximize} \sum \mathrm{Tt}=1 \sum \mathrm{nww}=13.14(\mathrm{w}) * \sum \mathrm{nss}=13.14(\mathrm{~s}) * \sum \mathrm{npp}=13.14(\mathrm{p}) *[¥ \mathrm{p}(\mathrm{t}) * \mathrm{Gwsp}(\mathrm{t})- \\
& \text { Cwspconv -Ywspconv } * \mathrm{Sconv}]
\end{aligned}
$$

In The first step for the optimization through genetic algorithms, we put a series of random input in the objective function and obtain answers. As its responses to the fitness entries indicated, fitness value can be calculated for each input.

In the next step, we input number of initial inputs (chromosome) which will incorporate in the crossover operation, in computer programming. The mathematical relationship which specifies number of incorporated solutions is given as:

\section{$\mathrm{Nc}=2 *$ round $\left(\mathrm{p}_{\mathrm{c}} * \mathrm{p}_{0} / 2\right)$}

Nc: number of chromosomes from initial population which incorporate in crossover operation

Pc: mutation rate (mutation probability)

P0: number of initial solutions

Then best solutions are chosen to incorporate in crossover operation. So that, solutions that are closer to expected optimization, will be selected. We will use roulette wheel for selecting. After selecting best solutions, if we don't meet expected optimized solution, we have to do crossover operation on the solutions in order to use previous step solution to reach new and closer optimized solution.

\section{4- Simulation results}

\subsection{Case study}

Virtual power plants studied in this thesis, including wind, solar, pumped storage and traditional power plants with gas turbine. Wind and solar power plants generation capacity are 
WM9.6 and MW6, respectively. Pumped storage (PHS) is modeled as a separate system with the ability to produce the energy equivalent to WM40.

Turbine and pump capacities are $8 \mathrm{MW}$ and 6MW. It should be noted that pumped storage power plant in this study is considered so that only has usability of pumped water from downstream basin and will not use any upstream basin.

$\mathrm{CPP}$ has 5670UAT turbine with capacity of $67.5 \mathrm{MW}$. Its minimum technical capacity is 2.5 $\mathrm{MW}$, its slope is $3 \mathrm{WM} / \mathrm{h}$. PPC cost curves is given in Figure 1 using piecewise linear approximation:

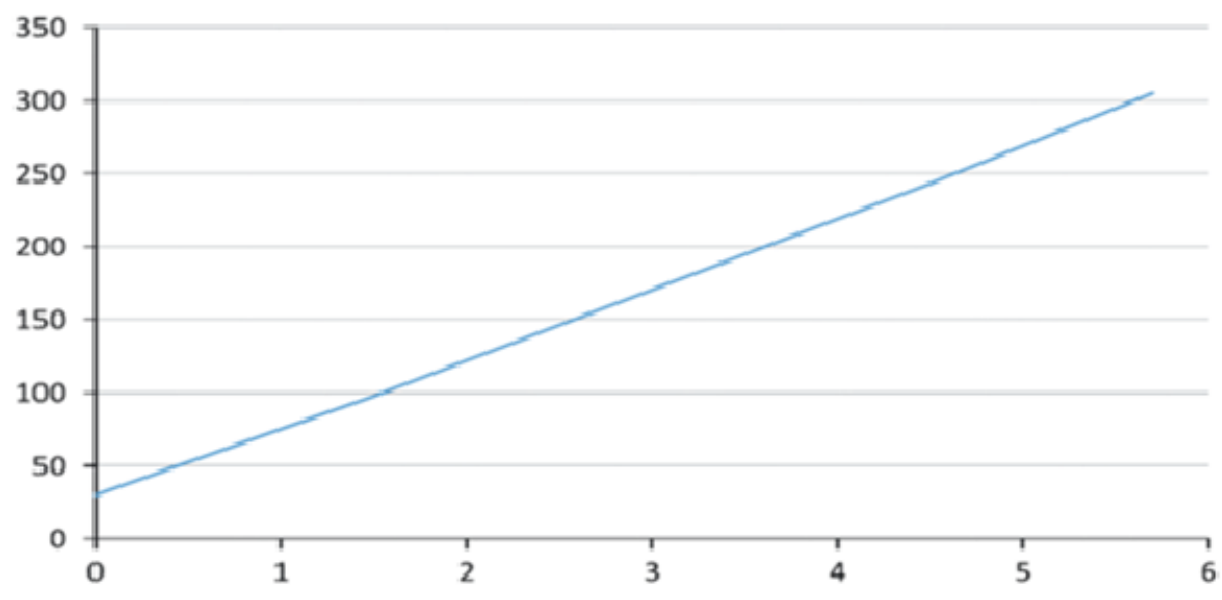

Figure 1: PPC cost curves using piecewise linear approximation

\subsection{Input parameters}

We will split a week to 168 one hour intervals. Bilateral contracts for electricity supply that virtual power plant should be responsible for it, is given in figure 2 Regarding all risks which affect the operation of this contract and may disrupt the delivery of electricity according to contract, minimum power delivered to network is $2.5 \mathrm{MW}$ which is considered minimum technical power of CPP. The total amount of transmitted power to the grid based on bilateral contract will be 726.8 Mwh.

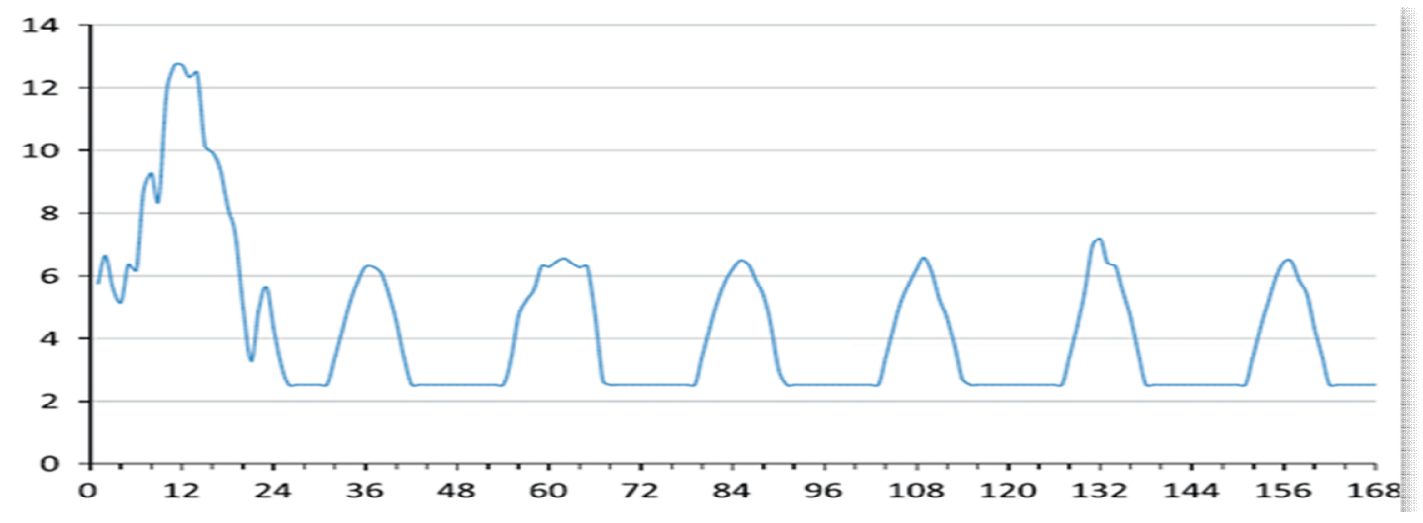

Figure 2: Power supply bilateral contracts

In addition to bilateral contracts, the virtual power plants will also participate in the electricity market. Prices are given in Figure 3 using five case studies with equal probability. Prices used in this paper are given based on the actual price and within 1 to 14 June 2009 and 31 May to 20 June 2010. 


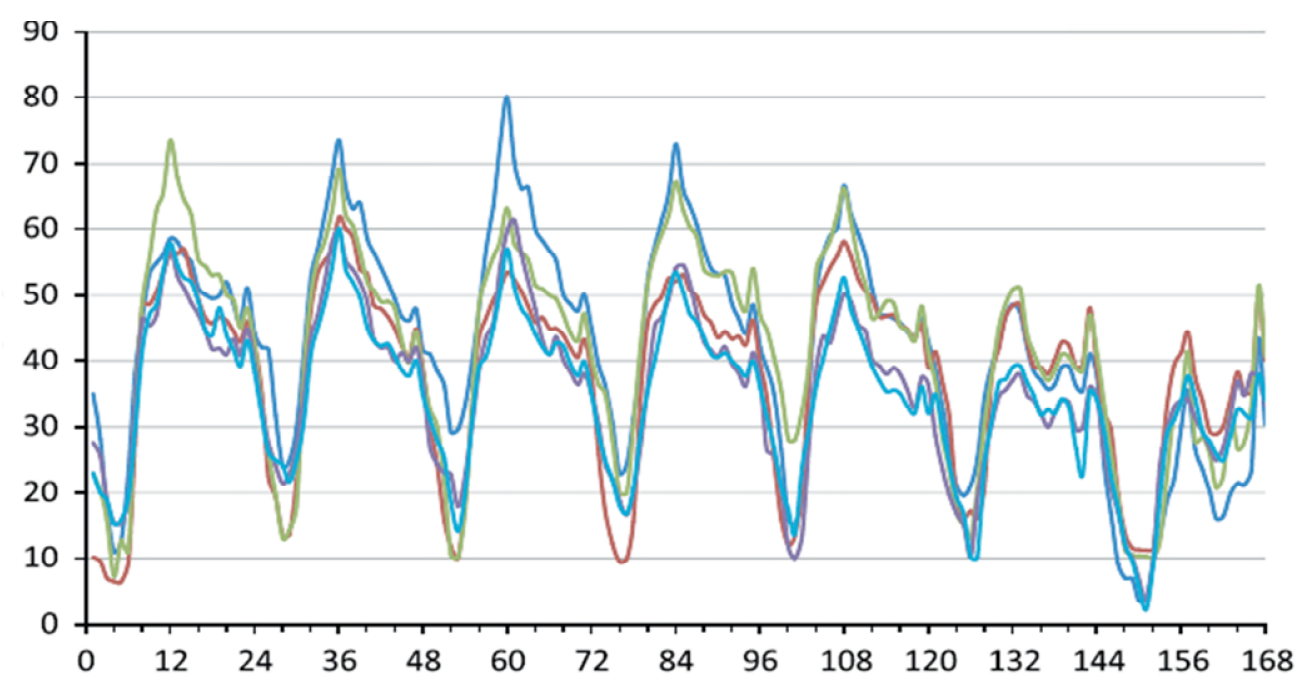

Case Study 1 turquoise, Case Study 2 Brown, Case Study 3 green, Case Study 4 purpl, Case Study 5 Blue

Figure 3: Evaluated prices in the electricity market

The estimated capacity of the wind power plant which is given in Figure 4, is taken from an actual PPW operating system in (Sibinik) city in Croatia. Period for which data were used is 31 to 20 June 2010 and 1 to 14 June 2009. This measuring is done in 5 weeks which each one includes a case study and occurrence probability of each is considered $20 \%$. Therefore, time framework that is used for price of electricity in this article is according to the correlation models and in accordance with the generation of electricity from Sibinik wind power.

Figure 5 shows the expected generation of solar power plants in five equal probability case studies. The solar potential data for the city (Sibinik) is considered at the time periods mentioned above

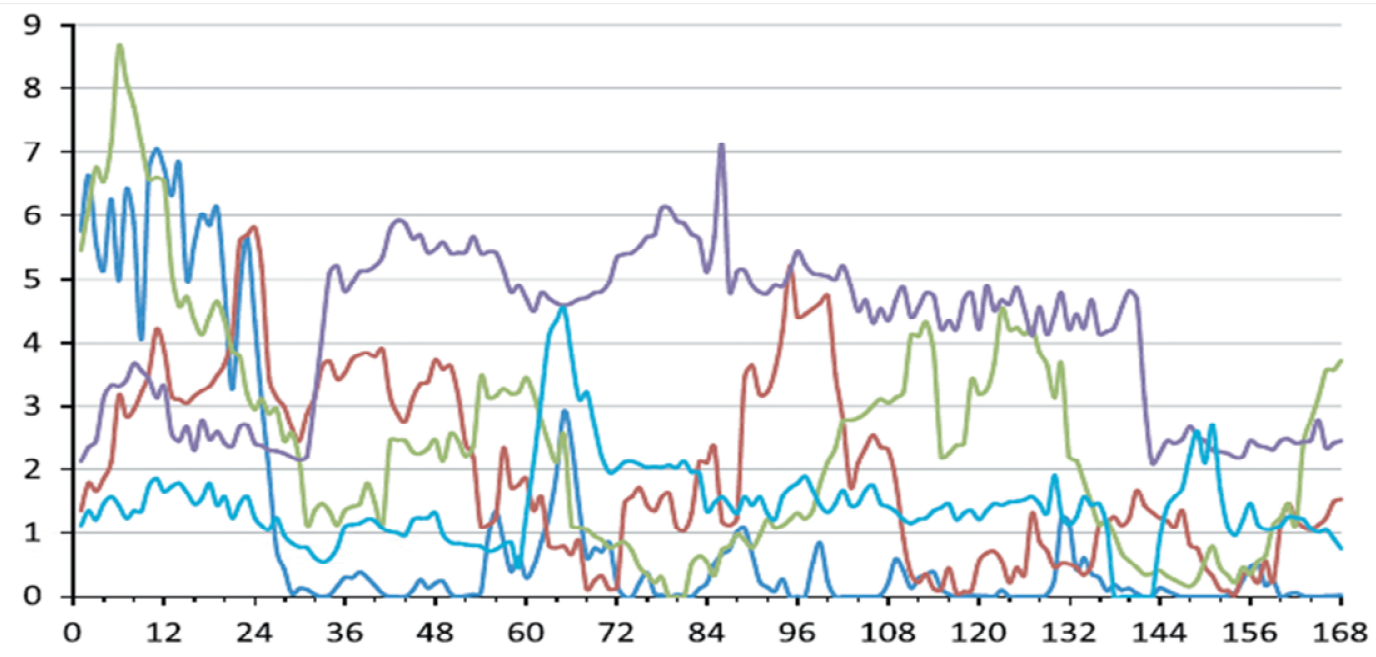

Case Study 1 turquoise, Case Study 2 Brown, Case Study 3 green, Case Study 4 purple, Case Study 5 Blue

Figure 4: The expected output of wind power plants 


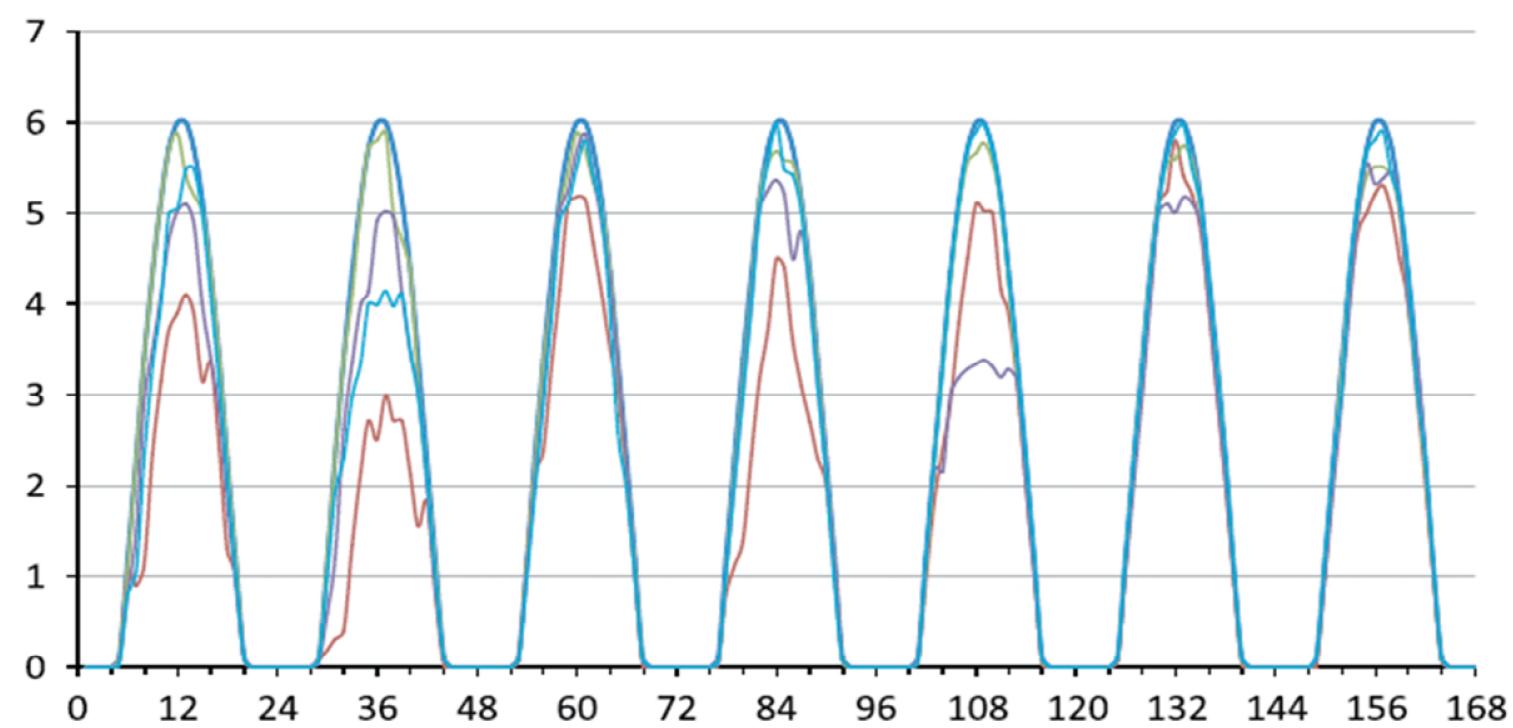

Case Study 1 turquoise, Case Study 2 Brown, Case Study 3 green, Case Study 4 purple, Case Study 5 Blue

Figure 5: The expected output of solar power plants

\section{Results}

Expected weekly profit is equal to 6215 euros. Since computed profit does not include bilateral contracts, expected profit becomes negative. If power contract value added is considered (30 euros per $30 \mathrm{MW}$ ), total weekly profit will be 1588 euros. In figure 6, achieved profit set at the end of every hour is shown. Negative profit in most of hours shows power bought to satisfy bilateral contracts, but also, we exploit bought power to pumping water to water storage basin PHS, in order sell generated power more expensive at peak time. Because of expense of the transferred power at peak time (presented in figure 1), the virtual power plant achieve its main profit at peak time. This means all achieved profit from market according to PHS system, is concentrated at peak time which is capable of changing the amount of power generation at peak time. This way of energy generation in a week long results increasing profit at the end of the week.

In figure 6, average of 5 case studies related to different generation resources cases is illustrated. Amounts of weekly power generation of all generation resources are integrated and results a 125 cases that their average is observable below. In figure 7 is specified that achieved profit at the end of the week is significant. In fact, virtual power plant operates so that at the end of the day that energy price is minimum it buys the energy and in the beginning of the day that energy price grows it will sell it. 


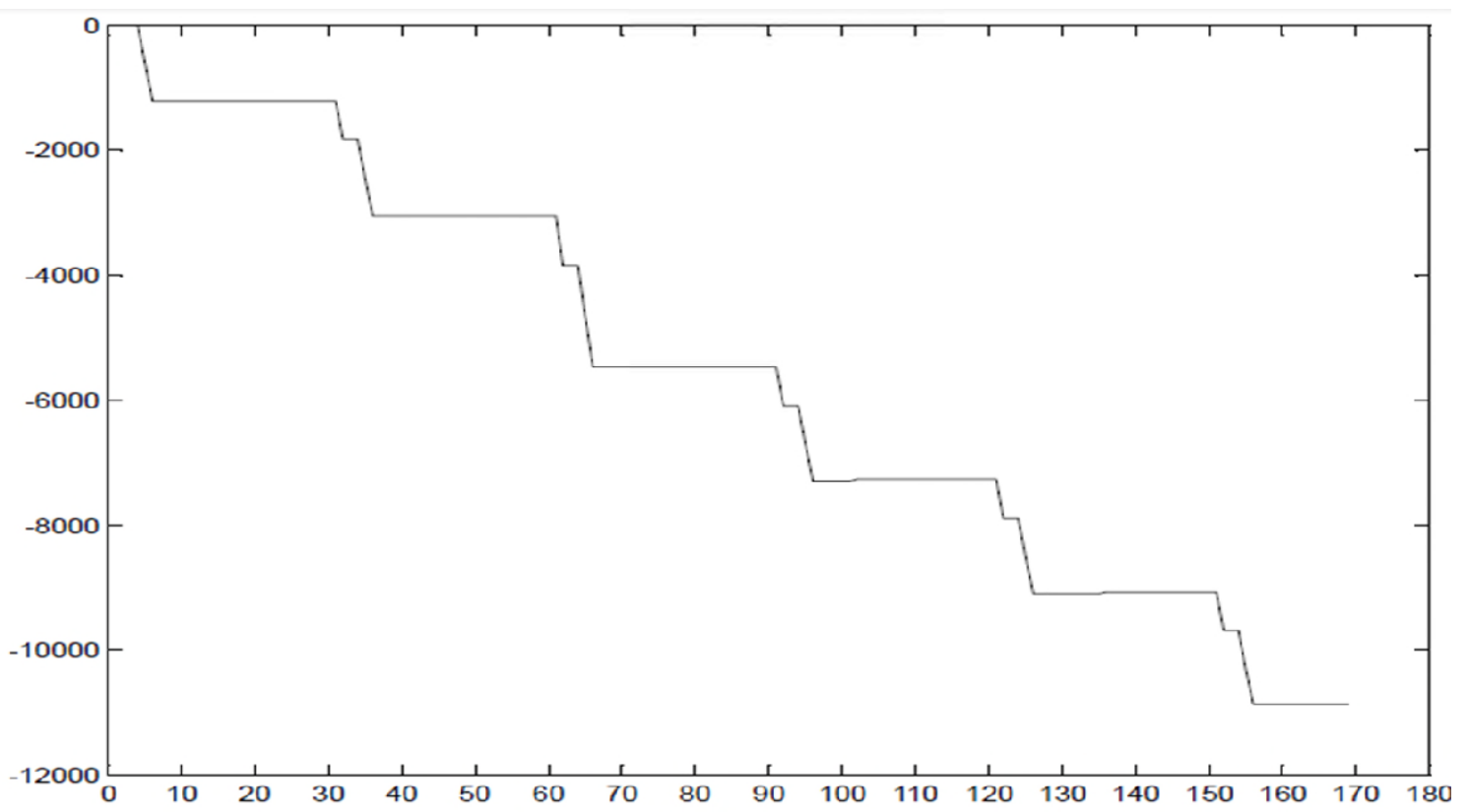

Figure 6: Achieved profit set in power market

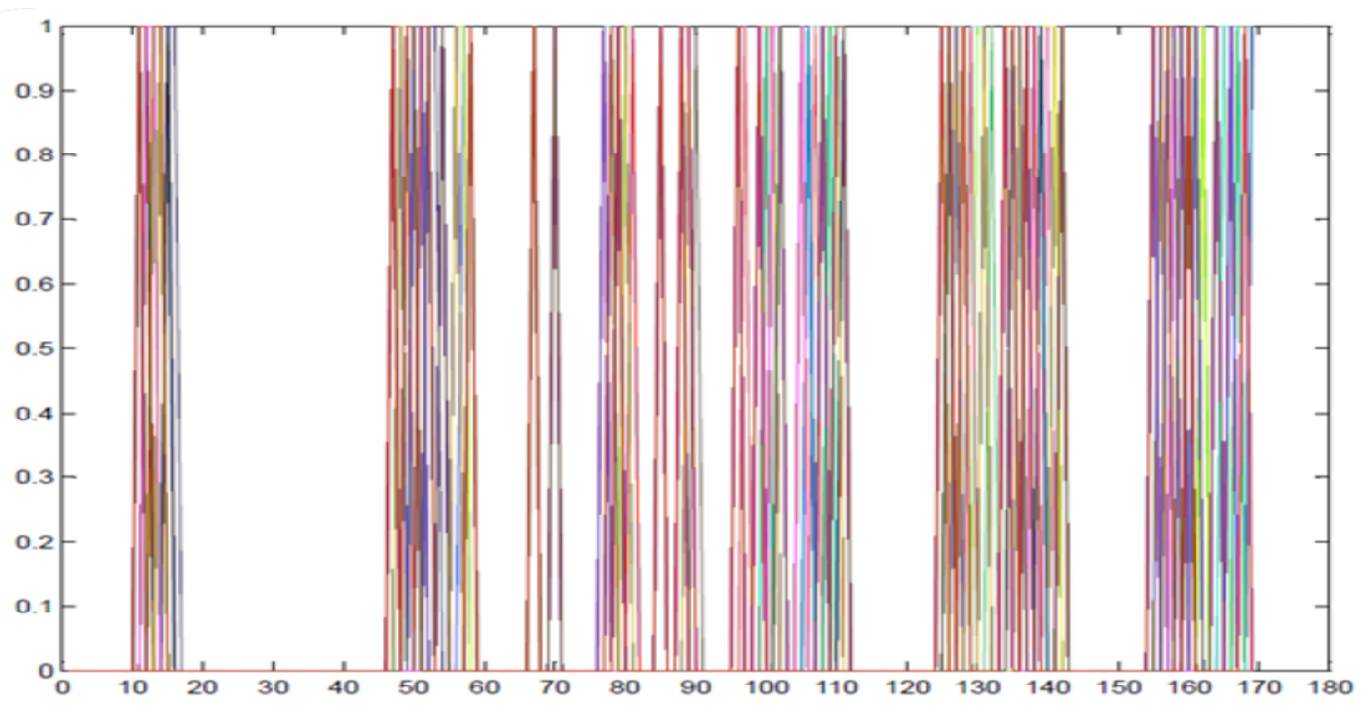

Figure 7: CPP generated in a week long

\section{Conclusion}

The advantages of virtual power plant are mentioned below separately. One of the most important points in a power system is keeping a power plant capacity in balance. A huge generation capacity, in load non-distributable resources like wind and solar power plant in contrast with load distributable ones, may cause decreasing reliability in bilateral contracts and in emergency cases, may lead to huge economic losses. So, increasing turbine capacity of pumped storage power plant will cause large and sudden changes in the wind speed and solar radiation can be compensated. As a result, the capacity of all power plants should determine regarding to technical reliability, the bilateral contracts and economic aspects. CPP's role is a backup power plant for the generating of shortage of virtual power plants and often is used when necessary. However, the investor must choose a power plant with cheap generation and ability to adapt with the virtual power plant. 
Although if it's possible to use an appropriate PHS system with high efficiency, it is not necessary to use CPP anymore, hence it can be saved on the expense of power plant.

In The CPP, it should be noted that if the cost of power generation is higher than the market price, it should be avoided exploiting it. FHS system performance should be planned precisely so it can realize expected profits in the assessments. The generation capacity of pumped storage power plant should be considered equivalent with its pump and turbine ability and we should strictly avoid unplanned investments in PHS. Another case mentioned in the study is electricity generation in excess of requirements due to the worst possible case, in reducing generation state because of fluctuating renewable energy generation. However, this increases the costs, but we can ensure fulfillment of bilateral contracts.

\section{References}

[1] Alvarado F.L, Meng J, DeMarco C.L, Mota W.S.2001: Stability analysis of interconnected power systems coupled with market dynamics, IEEE Transactions on Power Systems. Vol 16, Issue 4, pp. 695-701

[2] Awad B, Wu J , Jenkins N. Aug 2008: Control of distributed generation. E and I Elektrotechnik und Informationstechnik, vol. 125, pp. 409-414

[3] Beasley D, Bull D, Martin R. 1993: An Overview of Genetic Algorithms. Part 1, Fundamentals, University of Cardiff, Cardiff

[4] Bogner B, Abildgaard S.S, Andersen J.R. 2006: Power Distribution System," UK. Patent GB2402001, Sep. 20

[5] Braun M, Strauss P. 2008: A Review on Aggregation Approaches of Controllable Distributed Energy Units in Electrical Power Systems. International Journal of Distributed Energy Resources, Vol. 4, Issue 4, pp.297-319

[6] Braun M. 2009: Virtual Power Plant functionalities: demonstrations in a large laboratory for distributed energy resources. 20th International Conference on Electricity Distribution, Prague

[7] Cardell J.B. 2007: Distributed Resource Participation in Local Balancing Energy Markets. Power Tech, IEEE Lausanne

[8] Christensen J, Denton F, Garg A, Kamel S, Pacudan R. December 2005 : The role of renewable energy in a carbon-constrained world, Unep energy Pre-publication draft

[9] Donald J.Marihart. April 2001: Communication Technology Guidelines for EMS / SCADA System . IEEE Transaction Power Delivery, No.2, Vol.16

[10] Duque AJ, Castronuovo ED, Sanchez I, Usaola J.2011: Optimal operation of a pumpedstorage hydro plant that compensates the imbalances of a wind power producer. Elec Power System Res 2011;81(9):1767-77

[11] Fesmire B, July 2007: Energy Efficiency in the Power Grid. Renwable Energy Network ABB Inc

[12] Kapsali M, Kaldellis JK.2010: Combining hydro and variable wind power generation by means of pumped-storage under economically viable terms. Appl Energy 2010;87(11):347585

[13] Khan H.A, Herbert H.C. 2011: Active and Reactive Power Control of the Electronically Interfaced DG Sources for the Realization of a Virtual Power Plant, IEEE , 978-1-61284972-0/11

[14] Shi You . September 2010: Developing Virtual Power Plant for Optimized Distributed Energy Resources Operation and Integration, PhD Thesis, Technical University of Denmark

[15] Pedersen A.B, Hauksson E.B, Andersen P.B. 2010: Facilicating a generic communication interface to distributed energy resources: Mapping IEC 61850 to RESTful services. published in the Proceedings of International Conference on Smart Grid Communications, USA 
Bulletin de la Société Royale des Sciences de Liège, Vol. 85, 2015, p. 252 - 260

[16] Pandzic H, Kuzle I, Capuder T. 2013: Virtual power plant mid-term dispatch optimization. Elsevier journal, University of Zagreb, Faculty of Electrical Engineering and Computing, Department od Power Systems, Zagreb, Croatia 